\title{
In vitro influence of dietary protein and fructooligosaccharides on metabolism of canine fecal microbiota
}

\author{
Carlo Pinna ${ }^{1}$, Carla Giuditta Vecchiato ${ }^{1}$, Giuliano Zaghini', Monica Grandi', Eleonora Nannoni', \\ Claudio Stefanelli ${ }^{2}$ and Giacomo Biagi ${ }^{{ }^{*}}$
}

\begin{abstract}
Background: The present in vitro study investigated whether the utilization of fructooligosaccharides (FOS) may influence canine fecal microbial population in presence of diets differing in their protein content and digestibility. Fresh fecal samples were collected from five adult dogs, pooled, and incubated for $24 \mathrm{~h}$ with the undigested residue of three diets: 1, Low protein high digestibility diet (LP HD, crude protein (CP) $229 \mathrm{~g} / \mathrm{kg}$ ); 2, High protein high digestibility diet (HP HD, CP $304 \mathrm{~g} / \mathrm{kg}$ ); 3, High protein low digestibility diet (HP LD, CP $303 \mathrm{~g} / \mathrm{kg}$ ) that had been previously subjected to enzymatic digestion. In the in vitro fermentation study, there were six treatments: 1) LP HD; 2) HP HD 3) HP LD; 4) LP HD + FOS; 5) HP HD + FOS; 6) HP LD + FOS. Fructooligosaccharides were added at the final concentration of $1.5 \mathrm{~g} / \mathrm{L}$. Samples of fermentation fluid were collected at 6 and $24 \mathrm{~h}$ of incubation.

Results: Values of pH were reduced by FOS at 6 and $24 \mathrm{~h}(P<0.001)$; conversely, low protein digestibility and high dietary protein level resulted in higher $\mathrm{pH}$ at both sampling times $(P<0.001)$. At $24 \mathrm{~h}$, FOS lowered ammonia $(-10 \% ; P<0.001)$ and resulted $(P<0.05)$ in higher concentrations of total volatile fatty acids (VFA) $(+43 \%)$, acetic acid (+14\%), propionic acid (+75\%) and $n$-butyric acid (+372 \%). Conversely, at $24 \mathrm{~h}$, low protein digestibility resulted $(P<0.01)$ in lower concentrations of acetic acid $(-26 \%)$, propionic acid $(-37 \%)$ and total VFA $(-21 \%)$. Putrescine concentrations were increased at 6 and $24 \mathrm{~h}$ of fermentation by low protein digestibility $(+21$ and $22 \%$, respectively; $P<0.05)$ and FOS (+18 and $24 \%$, respectively; $P<0.01)$. After $24 \mathrm{~h}$ of fermentation, high dietary protein level resulted in lower counts of lactobacilli and enterococci $(-0.5$ and $-0.7 \mathrm{log}$ cells $/ \mathrm{mL}$, respectively; $P<0.05)$ whereas low protein digestibility tended to increase counts of $C$. perfringens ( $+0.2 \log$ cells $/ \mathrm{mL} ; P=0.07$ ).
\end{abstract}

Conclusions: Results from the present study showed that diets rich in protein may exert negative influences on the canine intestinal ecosystem, slightly increasing the presence of ammonia and reducing counts of lactobacilli and enterococci. Moreover, the presence of poorly digestible protein resulted in lower concentrations of VFA. Conversely, administration of FOS may improve metabolism of canine intestinal microbiota, reducing ammonia concentrations and enhancing VFA production.

Keywords: Dog, Dietary protein, Fructooligosaccharides, Intestinal microbiota

\footnotetext{
* Correspondence: giacomo.biagi@unibo.it

${ }^{1}$ Department of Veterinary Medical Sciences, University of Bologna, via Tolara

di Sopra 50, 40064 Ozzano Emilia, Italy

Full list of author information is available at the end of the article
} 


\section{Background}

The role of the microbial community that inhabits the large intestine is considered of fundamental importance in the maintenance of gastrointestinal tract health and host physiology. As some studies suggested, major functions of the gut microbiota include protection against potentially pathogenic microorganisms [1], detoxification of some catabolites introduced with the diet [2] and stimulation of the immune system [3]. Exogenous factors, diet above all, can shape the composition and metabolic activity of the intestinal microbiota [4]. Several strategies have been proposed to improve and maintain intestinal microbiota balance, among which the inclusion of prebiotic supplements. Prebiotics (mainly of vegetable origin) are often added to pet food, due to the increasing interest regarding companion animal health and welfare. Despite the fact that dogs are animals with a prevalent carnivorous diet, prebiotic supplements can enhance their gut health. Several positive effects have been seen in dogs receiving prebiotic non-digestible oligosaccharides, including stimulation of beneficial microbes [5], inhibition of undesirable bacteria [6], and reduction of protein-derived catabolites [7, 8]. Moreover, the intestinal microbiota of dogs can be negatively affected by the amount of undigested protein that reaches the colon and leads to putrefactive fermentation $[9,10]$.

The aim of this study was to assess the in vitro effects of diets differing in their protein content and digestibility, and containing or not a source of fructooligosaccharides (FOS), on the composition and activity of the canine fecal microbiota.

\section{Methods}

\section{In vitro study}

There were three experimental dry extruded diets (provided by Effeffe Pet Food S.p.A., Italy): 1) Low protein high digestibility diet (LP HD; crude protein (CP) $229 \mathrm{~g} / \mathrm{kg}$ dry matter (DM)); 2) High protein high digestibility diet (HP HD; CP $304 \mathrm{~g} / \mathrm{kg}$ DM); 3) High protein low digestibility diet (HP LD; CP $303 \mathrm{~g} / \mathrm{kg}$ DM). All diets were formulated based on the following ingredients: cereals, meat and meat by-products, oils and fat, protein plant extract, minerals and yeasts. The sole source of animal protein in the HD diets was a highly digestible swine meat meal (CP 685 g/kg DM; in vitro digestibility 0.71 ) whereas the LD diet contained the highly digestible swine meat meal (in the same amount as in the LP HD diet) and a poorly digestible meat meal from cattle and swine (CP $629 \mathrm{~g} / \mathrm{kg} \mathrm{DM}$; in vitro digestibility 0.31 ). Digestibility of meat meals was determined using the 2-step procedure proposed by Vervaeke et al. [11] and modified (2 h incubation with $\mathrm{HCl}$, pepsin and gastric lipase followed by $4 \mathrm{~h}$ with pancreatin and bile salts) as described by Biagi et al. [12].
The chemical composition of the experimental diets and their undigested residues is shown in Table 1.

The experimental diets were digested using the same 2step procedure that was used to determine digestibility of meat meals [12]. Digestibility coefficient was 0.84, 0.83 and 0.68 for LP HD, HP HD and HP LD, respectively. After in vitro digestion, the undigested residue of each diet was dried at $65{ }^{\circ} \mathrm{C}$ (until a constant dry weight was obtained) and later used in the in vitro fermentation study.

Five healthy adult dogs (household dogs, different breeds, living in different environments, between 1 and 6 years of age, average body weight: $17 \mathrm{~kg}$ ) were fed for 4 weeks with the LP HD diet added with FOS (from partially hydrolyzed inulin from chicory) at $15 \mathrm{~g} / \mathrm{kg}$ of food (Effeffe Pet Food Sp.A., Italy). Before the trial started, consent was obtained from each owner. The feeding of a commercial diet to the dogs that were used as fecal donors for the present in vitro study is a procedure that does not fall in the subject matter and scope of the actual legislation on the protection of animals used for scientific purposes. Fresh feces were collected from the five dogs immediately after excretion, pooled and suspended at $10 \mathrm{~g} / \mathrm{L}$ in pre-reduced Wilkins Chalgren Anaerobe Broth (WCAB). The fecal suspension was used to inoculate $(33 \mathrm{~mL} / \mathrm{L})$ five $30 \mathrm{ml}$ anaerobic serum bottles (containing $21 \mathrm{ml}$ of medium prepared according to Sunvold et al. [13]) per treatment.

In the in vitro fermentation study, there were 6 treatments: 1) LP HD; 2) HP HD; 3) HP LD; 4) LP HD + FOS; 5) HP HD + FOS; 6) HP LD + FOS. The anaerobic serum bottles contained the undigested residue of the diets, added at $10 \mathrm{~g} / \mathrm{L}$. Fructooligosaccharides (Beneo OPS, FOS from partially hydrolyzed inulin from chicory with a dp between 2 and 8; Beneo GmbH, Mannheim, Germany) were added at the final concentration of $1.5 \mathrm{~g} / \mathrm{L}$. These concentrations should reflect the amount of FOS that

Table 1 Chemical composition of experimental diets and undigested residues after in vitro digestion

\begin{tabular}{|c|c|c|c|c|c|c|c|}
\hline & \multirow{2}{*}{$\begin{array}{l}\text { DM, } \\
\mathrm{g} / \mathrm{kg}\end{array}$} & \multicolumn{6}{|c|}{$\mathrm{g} / \mathrm{kg}, \mathrm{DM}$ basis } \\
\hline & & $\begin{array}{l}\text { Crude } \\
\text { protein }\end{array}$ & $\begin{array}{l}\text { Ether } \\
\text { extract }\end{array}$ & $\begin{array}{l}\text { Crude } \\
\text { ashes }\end{array}$ & NDF & ADF & Starch \\
\hline \multicolumn{8}{|c|}{ Experimental diets } \\
\hline LP HD & 929 & 229 & 120 & 66 & 83 & 27 & 464 \\
\hline HP HD & 935 & 304 & 140 & 82 & 109 & 27 & 364 \\
\hline HP LD & 938 & 303 & 124 & 123 & 111 & 33 & 338 \\
\hline \multicolumn{8}{|c|}{ Undigested residues } \\
\hline LP HD & - & 159 & 35.7 & 215 & 539 & 175 & 41.4 \\
\hline HP HD & - & 174 & 47.2 & 259 & 481 & 124 & 28.7 \\
\hline HP LD & - & 212 & 24.4 & 339 & 411 & 125 & 9.0 \\
\hline
\end{tabular}

$L P H D$ low protein high digestibility, $H P H D$ high protein high digestibility, $H P$ $L D$ high protein low digestibility, $A D F$ acid detergent fiber, NDF neutral detergent fiber 
reach the hindgut when they are included in a commercial extruded food for dogs at a concentration of $15 \mathrm{~g} / \mathrm{kg}$ of food. In fact, if we estimate that the coefficient of digestibility for the dry matter of a commercial super premium dry food for dogs is 0.9 , and assuming that all the FOS will reach the large intestine, the ratio between the undigested food fraction and FOS in the hindgut will be approximately 10:1.5.

Fecal cultures $\mathrm{pH}$ was adjusted to 6.7 ; bottles were incubated for $24 \mathrm{~h}$ at $39{ }^{\circ} \mathrm{C}$ in an anaerobic cabinet (Anaerobic System, Forma Scientific Co., Marietta, USA; under a $\mathrm{N}_{2} 85 \%, \mathrm{CO}_{2} 10 \%, \mathrm{H}_{2} 5 \%$ atmosphere) and samples of fermentation fluid were collected from each bottle at 6 and $24 \mathrm{~h}$ and immediately frozen at $-80{ }^{\circ} \mathrm{C}$ for the determination of ammonia, volatile fatty acids (VFA), biogenic amines and bacterial counts. Additional fresh aliquots were used for $\mathrm{pH}$ measurement at 6 and $24 \mathrm{~h}$.

\section{Chemical and microbiological analyses}

Analyses of experimental diets and their undigested residues were performed according to AOAC standard methods [14] (method 950.46 for water, method 954.01 for CP, method 920.39 for ether extract, method 920.40 for starch, method 942.05 for crude ash). Fiber fractions were determined according to the procedure described by Van Soest et al. [15], where neutral detergent fiber (NDF) was assayed with a heat stable amylase and expressed inclusive of residual ash, acid detergent fiber (ADF) was expressed inclusive of residual ash.

Ammonia was measured using a commercial kit (Urea/ BUN - Color, BioSystems S.A., Barcelona, Spain). Volatile fatty acids were analyzed by gas chromatography [16]. For the determination of biogenic amines, samples were diluted 1:5 with perchloric acid $(0.3 \mathrm{M})$; biogenic amines were later separated by high performance liquid chromatography and quantified through fluorimetry, according to the method proposed by Stefanelli et al. [17].

The Fluorescence In Situ Hybridization technique was used to determine bacterial counts. For this purpose, ready-to-use commercial kits (BioVisible B.V., Groeningen,
Netherlands) containing specific FITC-labeled probes for the enumeration of enterococci (E. faecalis $+E$. faecium), Enterobacteriaceae, Clostridium perfringens, Bifidobacterium spp. and Lactobacillus spp. were used. The slides were evaluated with a Nikon Eclipse E-600 epifluorescence microscope, equipped with FITC specific filter.

\section{Statistical analyses}

Data were analyzed by three-way ANOVA, with dietary protein content and digestibility and FOS as the main effects. Differences were considered statistically significant at $P<0.05$. All the statistical computations were performed with Statistica 10.0 (Stat Soft Italia, Italy). Due to the fact that the experimental design did not comprise a low protein low digestibility (LP LD) diet, interactions among main effects were not reported. The reason for the absence of the LP LD diet is that the experimental diets used in the present in vitro study were also used in an in vivo study with dogs, where the feeding of a low protein low digestibility diet would have been unacceptable for ethical reasons.

\section{Results}

The $\mathrm{pH}$ values at 6 and $24 \mathrm{~h}$ of incubation are shown in Table 2. After $6 \mathrm{~h}$ of incubation, $\mathrm{pH}$ was influenced $(P<0.001)$ both by protein level $(6.26$ vs. 6.61 for LP and HP, respectively) and digestibility (6.38 vs. 6.71 for $\mathrm{HD}$ and LD, respectively), and reduced by FOS supplementation (6.23 vs. 6.75). At $24 \mathrm{~h}, \mathrm{pH}$ values were lowered $(P<0.001)$ by high protein digestibility ( 5.98 vs. 6.30$)$, low dietary protein level (6.09 vs. 6.40) and FOS (5.96 vs. 6.44).

The concentrations of ammonia are shown in Table 2. At $6 \mathrm{~h}$ of incubation, ammonia concentration was reduced by the presence of FOS (34.6 vs. $37.0 \mathrm{mmol} / \mathrm{L} ; P<0.01$ ). After $24 \mathrm{~h}$, ammonia was reduced by FOS (36.4 vs. $40.3 \mathrm{mmol} / \mathrm{L} ; P<0.001)$ and influenced by protein digestibility (38.9 vs. $37.4 \mathrm{mmol} / \mathrm{L}$ for $\mathrm{HD}$ and LD, respectively; $P<0.01)$ and protein level $(38.5$ vs. $38.1 \mathrm{mmol} / \mathrm{L}$ for $\mathrm{HP}$ and LP, respectively; $P<0.05)$.

Concentrations of VFA are shown in Table 3. After $6 \mathrm{~h}$ of fermentation, FOS reduced concentrations of propionic

Table $2 \mathrm{pH}$ values and ammonia concentrations ( $\mathrm{mmol} / \mathrm{L}$ ) after 6 and $24 \mathrm{~h}$ of the vitro study ${ }^{\mathrm{a}}$

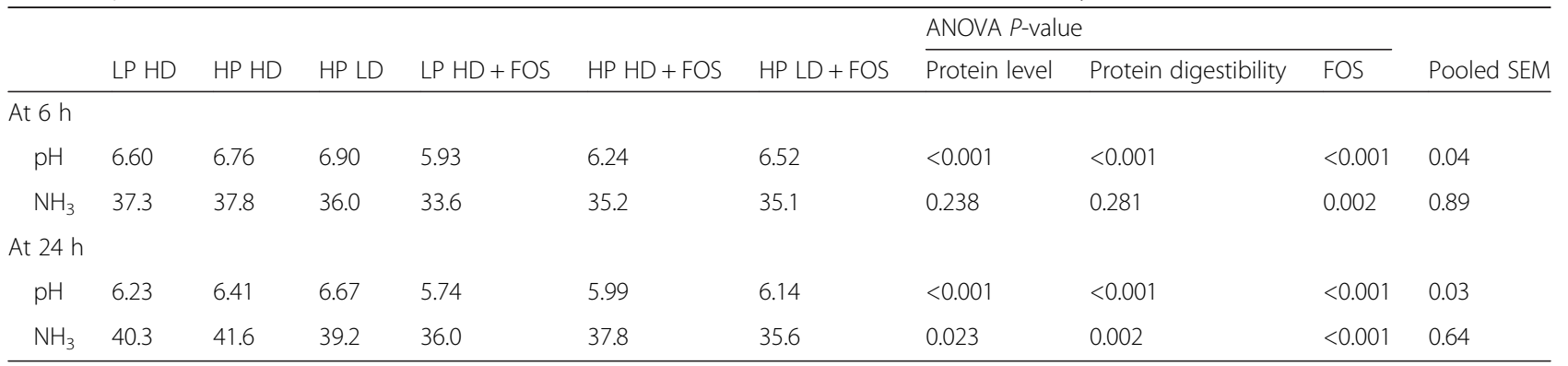

$L P H D$ low protein high digestibility, HP HD high protein high digestibility, $H P L D$ high protein low digestibility, FOS fructooligosaccharides

${ }^{a}$ Values are the means of five bottles per treatment 
Table 3 Concentrations ( $\mathrm{mmol} / \mathrm{L}$ ) of volatile fatty acids at 6 and $24 \mathrm{~h}$ of the vitro study ${ }^{\mathrm{a}}$

\begin{tabular}{|c|c|c|c|c|c|c|c|c|c|c|}
\hline & \multirow[b]{2}{*}{ LP HD } & \multirow[b]{2}{*}{$\mathrm{HP} \mathrm{HD}$} & \multirow[b]{2}{*}{ HP LD } & \multirow[b]{2}{*}{$L P H D+F O S$} & \multirow[b]{2}{*}{$\mathrm{HP} \mathrm{HD}+\mathrm{FOS}$} & \multirow[b]{2}{*}{ HP LD + FOS } & \multicolumn{3}{|c|}{ ANOVA $P$-value } & \multirow[b]{2}{*}{ Pooled SEM } \\
\hline & & & & & & & Protein level & Protein digestibility & FOS & \\
\hline \multicolumn{11}{|l|}{$6 \mathrm{~h}$} \\
\hline Acetic acid & 15.2 & 17.6 & 9.7 & 16.8 & 11.2 & 8.8 & 0.304 & 0.005 & 0.220 & 1.44 \\
\hline Propionic acid & 1.58 & 1.56 & 1.09 & 1.04 & 0.59 & 0.52 & 0.236 & 0.214 & $<0.001$ & 0.18 \\
\hline iso-Butyric acid & 0.16 & 0.15 & 0.12 & 0.10 & 0.02 & 0.03 & 0.246 & 0.731 & 0.011 & 0.04 \\
\hline n-Butyric acid & 2.81 & 3.10 & 1.04 & 7.47 & 2.33 & 2.12 & 0.040 & 0.304 & 0.052 & 1.04 \\
\hline iso-Valeric acid & 0.03 & 0.01 & 0.04 & 0.01 & 0.01 & 0.01 & 0.207 & 0.304 & 0.135 & 0.01 \\
\hline Total VFA & 19.8 & 22.4 & 12.0 & 25.5 & 14.2 & 11.4 & 0.090 & 0.019 & 0.809 & 2.30 \\
\hline $\mathrm{C} 2: \mathrm{C} 3$ & 10.3 & 11.8 & 9.1 & 16.4 & 23.8 & 26.9 & 0.457 & 0.879 & 0.030 & 5.53 \\
\hline $\mathrm{C} 2+n-\mathrm{C} 4: \mathrm{C} 3$ & 12.3 & 13.7 & 10.0 & 23.6 & 28.1 & 30.3 & 0.616 & 0.997 & 0.005 & 5.43 \\
\hline \multicolumn{11}{|l|}{$24 \mathrm{~h}$} \\
\hline Acetic acid & 27.4 & 24.2 & 18.8 & 28.1 & 33.2 & 21.8 & 0.862 & 0.003 & 0.037 & 2.23 \\
\hline Propionic acid & 7.65 & 6.37 & 1.93 & 12.12 & 10.88 & 7.86 & 0.105 & $<0.001$ & $<0.001$ & 0.66 \\
\hline iso-Butyric acid & 0.09 & 0.52 & 0.16 & 0.27 & 0.09 & 0.27 & 0.201 & 0.500 & 0.483 & 0.11 \\
\hline n-Butyric acid & 2.12 & 3.79 & 1.11 & 9.72 & 7.97 & 10.67 & 0.880 & 0.848 & $<0.001$ & 0.90 \\
\hline iso-Valeric acid & 0.44 & 0.68 & 0.23 & 0.44 & 0.11 & 0.22 & 0.950 & 0.303 & 0.106 & 0.14 \\
\hline Total VFA & 37.7 & 35.5 & 22.3 & 50.6 & 52.3 & 40.8 & 0.864 & 0.001 & $<0.001$ & 2.66 \\
\hline$C 2: C 3$ & 3.65 & 3.81 & 9.61 & 2.35 & 3.07 & 2.77 & 0.585 & 0.006 & $<0.001$ & 0.70 \\
\hline $\mathrm{C} 2+n-\mathrm{C} 4: \mathrm{C} 3$ & 3.91 & 4.40 & 10.22 & 3.14 & 3.86 & 4.13 & 0.409 & 0.001 & 0.001 & 0.65 \\
\hline
\end{tabular}

LP HD low protein high digestibility, HP HD high protein high digestibility, HP LD high protein low digestibility, FOS fructooligosaccharides, VFA volatile fatty acids, $C 2 / C 3$ acetic acid/propionic acid ratio, $C 2+n-C 4 / C 3$ acetic acid $+n$-butyric acid/propionic acid ratio

${ }^{a}$ Values are the means of five bottles per treatment

and iso-butyric acid $(0.73$ vs. $1.45 \mathrm{mmol} / \mathrm{L}$ and 0.05 vs. $0.15 \mathrm{mmol} / \mathrm{L}$, respectively; $P<0.05)$. The high dietary protein level resulted in lower concentrations of $n$-butyric acid $(2.21$ vs. $5.14 \mathrm{mmol} / \mathrm{L} ; P<0.05)$ whereas low protein digestibility determined lower concentrations of acetic acid and total VFA ( 9.1 vs. $15.3 \mathrm{mmol} / \mathrm{L}$ and $11.6 \mathrm{vs}$. $20.7 \mathrm{mmol} / \mathrm{L}$, respectively; $P<0.05$ ). The acetic to propionic acid ratio and acetic acid $+n$-butyric acid to propionic acid ratio were increased $(P<0.05)$ by FOS. After $24 \mathrm{~h}$ of fermentation, FOS resulted $(P<0.001)$ in higher concentrations of total VFA ( 47.1 vs. $32.9 \mathrm{mmol} / \mathrm{L} ; P<0.001)$, acetic acid ( 27.2 vs. $23.9 \mathrm{mmol} / \mathrm{L} ; P<0.05)$, propionic acid ( 9.93 vs. $5.69 \mathrm{mmol} / \mathrm{L} ; P<0.05)$, and $n$-butyric acid $(9.53$ vs. $2.56 \mathrm{mmol} / \mathrm{L} ; P<0.001)$. Both the acetic to propionic acid ratio and acetic acid + n-butyric acid to propionic acid ratio were reduced by FOS and increased by low protein digestibility $(P<0.01)$. Low protein digestibility also resulted $(P<0.01)$ in lower concentrations of total VFA (33.9 vs. $43.1 \mathrm{mmol} / \mathrm{L})$, acetic acid (20.7 vs. $28.0 \mathrm{mmol} / \mathrm{L}$ ) and propionic acid (5.63 vs. $8.89 \mathrm{mmol} / \mathrm{L}$ ).

With regard to biogenic amines (Table 4), spermine concentrations after $6 \mathrm{~h}$ of incubation were affected by protein level $(39.9$ vs. $32.3 \mu \mathrm{mol} / \mathrm{mL}$ for LP and HP, respectively; $P<0.001$ ). Putrescine concentrations were increased at 6 and $24 \mathrm{~h}$ of fermentation by low protein digestibility $(+21$ and $+22 \%$, respectively; $P<0.05)$ and FOS $(+18$ and $+24 \%$, respectively; $P<0.01)$. At $24 \mathrm{~h}$, low protein digestibility resulted in higher spermidine $(97.8$ vs $71.4 \mu \mathrm{mol} /$ $\mathrm{mL} ; P<0.001)$, whereas FOS induced an increase in spermine concentration $(19.8$ vs. $9.7 \mu \mathrm{mol} / \mathrm{mL} ; P<0.001)$. Cadaverine concentrations were not affected by treatments.

Bacterial counts after 6 and $24 \mathrm{~h}$ of incubation are shown in Table 5 . At $6 \mathrm{~h}$, high dietary protein level resulted in lower counts of Clostridium perfringens (5.90 vs. $6.71 \log$ cells $/ \mathrm{mL} ; P<0.05)$, Lactobacillus spp. (3.46 vs. $4.42 \log$ cells $/ \mathrm{mL} ; P<0.001)$ and enterococci (7.71 vs. $8.52 \log$ cells $/ \mathrm{mL} ; P=0.026)$. After $24 \mathrm{~h}$ of fermentation, high dietary protein level resulted in lower counts of Lactobacillus spp. (3.2 vs. $3.7 \log$ cells $/ \mathrm{mL}, P<0.05)$ and enterococci $(7.5$ vs. 8.2 $\log$ cells $/ \mathrm{mL} ; P<0.05)$, low protein digestibility tended to increase counts of $C$. perfringens ( 6.0 vs. $5.8 \log$ cells $/ \mathrm{mL}$; $P=0.07)$ and FOS resulted in higher Enterobacteriaceae (8.6 vs. $8.2 \log$ cells $/ \mathrm{mL} ; P<0.001$ ) and lower Lactobacillus spp. (3.1 vs. $3.6 \log$ cells $/ \mathrm{mL} ; P<0.001$ ). Bifidobacteria were not affected by treatments (data not shown) and averaged 6.72 and $6.85 \log$ cells $/ \mathrm{mL}$ at 6 and $24 \mathrm{~h}$ of incubation, respectively.

\section{Discussion}

Due to ethical and economic concerns regarding the use of animals for scientific purposes, in vitro fermentation 
Table 4 Concentrations of biogenic amines ( $\mu \mathrm{mol} / \mathrm{L})$ at 6 and $24 \mathrm{~h}$ of the in vitro study ${ }^{\mathrm{a}}$

\begin{tabular}{|c|c|c|c|c|c|c|c|c|c|c|}
\hline & \multirow[b]{2}{*}{ LP HD } & \multirow[b]{2}{*}{ HP HD } & \multirow[b]{2}{*}{ HP LD } & \multirow[b]{2}{*}{ LP HD + FOS } & \multirow[b]{2}{*}{$\mathrm{HP} \mathrm{HD}+\mathrm{FOS}$} & \multirow[b]{2}{*}{ HP LD + FOS } & \multicolumn{3}{|c|}{ ANOVA $P$-value } & \multirow[b]{2}{*}{ Pooled SEM } \\
\hline & & & & & & & Protein level & Protein digestibility & FOS & \\
\hline \multicolumn{11}{|l|}{ At $6 \mathrm{~h}$} \\
\hline Putrescine & 443 & 542 & 601 & 591 & 577 & 705 & 0.241 & 0.013 & 0.003 & 35.2 \\
\hline Cadaverine & 18.6 & 25.8 & 19.0 & 23.3 & 12.9 & 22.5 & 0.413 & 0.631 & 0.133 & 4.62 \\
\hline Spermidine & 63.2 & 68.8 & 65.0 & 68.3 & 66.4 & 59.4 & 0.839 & 0.519 & 0.133 & 6.56 \\
\hline Spermine & 40.3 & 34.5 & 35.6 & 41.2 & 28.6 & 29.0 & $<0.001$ & 0.422 & 0.080 & 2.08 \\
\hline \multicolumn{11}{|l|}{ At $24 \mathrm{~h}$} \\
\hline Putrescine & 550 & 617 & 790 & 780 & 775 & 863 & 0.514 & 0.013 & $<0.001$ & 50.0 \\
\hline Cadaverine & 31.1 & 20.9 & 20.3 & 24.2 & 24.5 & 22.3 & 0.734 & 0.220 & 0.720 & 6.40 \\
\hline Spermidine & 105.4 & 65.6 & 67.5 & 94.0 & 82.6 & 66.0 & 0.002 & 0.128 & 0.769 & 6.18 \\
\hline Spermine & 11.9 & 5.8 & 11.6 & 25.8 & 20.6 & 17.1 & 0.055 & 0.519 & $<0.001$ & 2.14 \\
\hline
\end{tabular}

LP HD low protein high digestibility, HP HD high protein high digestibility, HP LD high protein low digestibility, FOS fructooligosaccharides

avalues are the means of five bottles per treatment

models have been widely used to investigate the effects of dietary factors on gut microbiota, both in humans and animals [13, 18-22]. The aim of the present study was to investigate whether FOS may influence fecal microbial population of dogs in presence of diets differing in their protein content and digestibility.

The reduction of colonic luminal $\mathrm{pH}$ has potential positive effects on the host gut health, due to the inhibiting effect that an acidic environment has on some harmful bacteria [23]; moreover, a low $\mathrm{pH}$ can induce a shift from ammonia to ammonium ions, thus limiting the absorption of ammonia across the intestinal mucosa [24]. In the present study, $\mathrm{pH}$ was reduced by FOS whereas high dietary protein level and low protein digestibility resulted in higher $\mathrm{pH}$ values. The higher $\mathrm{pH}$ values that were found in bottles containing the high dietary protein level may be the consequence of the slightly higher ammonia concentrations that were observed at $24 \mathrm{~h}$. On the other hand, at 6 and $24 \mathrm{~h}$, low protein digestibility resulted in lower VFA concentrations and this finding may explain the higher $\mathrm{pH}$ values observed in the vessels containing the LD diets. It is known that bacterial fermentation of carbohydrates leads to the production of VFA and lactic acid which, in turn, lower the intestinal $\mathrm{pH}$. In fact, in the present study, FOS resulted in higher concentrations of VFA. In a previous in vitro experiment with canine fecal inoculum, FOS fermentation resulted in lower $\mathrm{pH}$ values than control [12]. Conversely, in another in vitro study, FOS did not affect $\mathrm{pH}$ when fermented in presence of feline fecal inoculum [25]. Moreover, in several in vivo studies with dogs, dietary supplementation with FOS failed to affect fecal $\mathrm{pH}$ [2629]. However, it is well known that the concentration of VFA can vary while digesta move along the intestine as these metabolites are absorbed by the intestinal mucosa [30]. According to Topping and Clifton [31], only $5 \%$ of

Table 5 Bacterial counts (log cells $/ \mathrm{mL}$ ) at 6 and 24 h of the in vitro study ${ }^{\mathrm{a}}$

\begin{tabular}{|c|c|c|c|c|c|c|c|c|c|c|}
\hline & \multirow[b]{2}{*}{ LP HD } & \multirow[b]{2}{*}{ HP HD } & \multirow[b]{2}{*}{ HP LD } & \multirow[b]{2}{*}{$\mathrm{LPHD}+\mathrm{FOS}$} & \multirow[b]{2}{*}{$\mathrm{HPHD}+\mathrm{FOS}$} & \multirow[b]{2}{*}{ HP LD + FOS } & \multicolumn{3}{|c|}{ ANOVA P-value } & \multirow[b]{2}{*}{ Pooled SEM } \\
\hline & & & & & & & Protein level & Protein digestibility & FOS & \\
\hline \multicolumn{11}{|l|}{ At $6 \mathrm{~h}$} \\
\hline Enterobacteriaceae & 8.60 & 7.59 & 8.60 & 8.70 & 8.90 & 8.81 & 0.404 & 0.345 & 0.177 & 0.47 \\
\hline C. perfringens & 6.74 & 5.20 & 6.59 & 6.68 & 5.93 & 5.89 & 0.049 & 0.231 & 0.976 & 0.55 \\
\hline Lactobacillus spp. & 4.31 & 3.60 & 3.41 & 4.53 & 3.45 & 3.37 & $<0.001$ & 0.303 & 0.929 & 0.13 \\
\hline Enterococci & 8.54 & 7.20 & 7.80 & 8.50 & 7.81 & 8.13 & 0.026 & 0.297 & 0.405 & 0.43 \\
\hline \multicolumn{11}{|l|}{ At $24 \mathrm{~h}$} \\
\hline Enterobacteriaceae & 8.31 & 8.43 & 7.94 & 8.69 & 8.51 & 8.69 & 0.746 & 0.097 & $<0.001$ & 0.09 \\
\hline C. perfringens & 5.83 & 5.79 & 5.98 & 5.81 & 5.88 & 6.08 & 0.918 & 0.068 & 0.499 & 0.10 \\
\hline Lactobacillus spp. & 4.20 & 3.34 & 3.16 & 3.16 & 3.00 & 3.12 & 0.002 & 0.836 & $<0.001$ & 0.14 \\
\hline Enterococci & 8.04 & 7.86 & 7.69 & 8.30 & 6.72 & 7.66 & 0.040 & 0.349 & 0.371 & 0.41 \\
\hline
\end{tabular}

LP HD low protein high digestibility, HP HD high protein high digestibility, HP LD high protein low digestibility, FOS fructooligosaccharides

${ }^{a}$ Values are the means of five bottles per treatment 
total VFA produced in the intestine by bacterial fermentation may be recovered in the feces. This could explain the discrepancy in $\mathrm{pH}$ values and VFA concentrations often found between in vitro and in vivo studies.

Fermentation of experimental diets resulted in different VFA concentrations. After $24 \mathrm{~h}$ of fermentation, the presence of FOS resulted in higher concentrations of acetic, propionic and $n$-butyric acids. In particular, higher intestinal concentrations of $n$-butyric acid may improve the animal's intestinal health because this acid is the main energy source for the epithelial cells of the terminal ileum [32] and hindgut [33]. In agreement with our findings, other authors reported higher fecal concentrations of total VFA [34], $n$-butyric acid [26, 35] and propionic acid, the latter under both in vitro [12] and in vivo $[26,27]$ conditions, when FOS were added to canine diets. With regard to dietary protein, VFA production was reduced by low protein digestibility but was not influenced by dietary protein level. This result suggests that microbial fermentations in the canine hindgut may be affected more by protein digestibility than by protein content of the diet. However, it also has to be noticed that LD diets contained slightly less starch than the HD diets, which may partially explain the different VFA concentrations that were observed. In a recent study with dogs, feeding a high-protein greaves-meal diet (609 $\mathrm{g}$ of CP per $\mathrm{kg}$ of diet) resulted in lower acetic and propionic acids and higher branched-chain fatty acids (BCFA) fecal concentrations than control (control diet contained $264 \mathrm{~g}$ of $\mathrm{CP}$ per $\mathrm{kg}$ of diet), but digestibility of experimental diets was not evaluated [36]. In the present study, LD diets reduced concentrations of both acetic and propionic acids whereas HP diets had no significant effect on the concentrations of these microbial metabolites.

As already mentioned, high dietary protein level resulted in higher ammonia concentrations. Higher fecal ammonia concentrations in dogs fed protein-rich diets were reported by other authors $[9,28,36,37]$. In a recent study, Nery et al. [10] reported greater fecal ammonia concentrations in dogs fed diets containing poultry meal if compared with highly digestible wheat gluten diets; in the same study, fecal ammonia concentrations were increased when dogs were fed diets containing high levels of protein (CP $390 \mathrm{~g} / \mathrm{kg}$ of diet) if compared with low-protein diets (CP $220 \mathrm{~g} / \mathrm{kg}$ of diet). In another study, Hesta et al. [28] noticed increased fecal ammonia concentrations in dogs fed diets supplemented with meat and bone meal or greaves meal but not when diets were supplemented with poultry meal. Interestingly, in the present study, low protein digestibility did not increase ammonia concentrations. This result is difficult to explain considering the fact that the undigested residue of the LD diet contained more protein $(212 \mathrm{~g} / \mathrm{kg}$ of $\mathrm{CP})$ than the undigested fraction of the
HD diets (159 and $174 \mathrm{~g} / \mathrm{kg}$ of CP for LP and HP, respectively). Ammonia is a toxic compound that can be the cause of reduced villus height [38] and even have carcinogenic effects [39]. In humans [40, 41] and dogs [7], the treatment of renal and hepatic failure involves reducing the circulating ammonia by using prebiotics or antibiotics, thus reducing ammonia production by intestinal bacteria. In fact, prebiotic ingredients represent a source of energy for saccharolytic bacteria [42, 43] and contribute to restricting proteolytic fermentation and promoting nitrogen utilization by colonic bacteria [7]. In the present study, ammonia concentrations were reduced by FOS both after 6 and $24 \mathrm{~h}$ of incubation. Conversely, in previous in vitro studies with canine [12] and feline [25] fecal inocula, the incubation of FOS failed to reduce ammonia concentrations. Inconsistent results have been obtained also under in vivo conditions when dogs were fed diets containing FOS. In fact, while Flickinger et al. [27] observed that FOS tended to reduce fecal ammonia concentrations in dogs, other authors $[8,26,28,44,45]$ failed to observe any positive influence of FOS on canine fecal ammonia. It seems evident that the effect of FOS on intestinal and fecal ammonia concentrations in dogs can be influenced by several variables, including the amount of FOS used, as well as dietary and environmental factors. Moreover, like VFA, ammonia is easily absorbed through the intestinal mucosa and its fecal concentration might not be representative of the gut concentration.

While VFA are derived from both protein and carbohydrate fermentation, BCFA derive exclusively from branched amino acids bacterial breakdown [46-48]. It has been shown that metabolites deriving from bacterial fermentation of protein in the gut are affected both by dietary protein content and source in humans [49] as well as in dogs $[10,36,50]$ and other carnivorous animals, such as cheetahs [21]. However, in the present study, iso-butyric and iso-valeric acids concentrations were not affected by protein level and digestibility. Conversely, at $6 \mathrm{~h}$ of fermentation, the presence of FOS resulted in a reduction of iso-butyric acid concentration. This finding is in accordance with Depauw et al. [21] who reported a reduction of total BCFA when cheetah fecal inoculum was incubated in presence of FOS.

Biogenic amines are putrefactive compounds derived from amino acid and peptide decarboxylation [51]. Biogenic amines such as histamine and tyramine play important roles in maintaining the physiology of animals but also have toxicological properties, therefore constituting a potential health risk [52]. Moreover, other biogenic amines such as cadaverine, putrescine, spermidine and spermine do not seem to have direct toxic effects but can potentiate histamine and tyramine toxicity by competing with detoxifying enzymes [53]. In the present study, fermentation of FOS resulted in increased concentrations of putrescine 
and spermine. This finding is in apparent contradiction with the reduction of other proteolytic compounds, such as ammonia and iso-butyric acid, that was observed in vessels containing FOS. Recently, in an in vitro study with feline fecal inoculum, fermentation of FOS, galacto-oligosaccharides and pectin resulted in increased concentrations of putrescine [25]. Similarly, Barry et al. [54] observed increased fecal concentrations of cadaverine and putrescine in cats receiving FOS or pectins. Beloshapka et al. [55] noticed an increase of fecal spermine in dogs receiving two different raw beef and chicken-based diets added with inulin and yeast cell wall. Moreover, Propst et al. [35] found higher fecal concentrations of biogenic amines in dogs fed increasing levels of FOS. Conversely, in the study by Flickinger et al. [27], feeding dogs with increasing levels of FOS did not affect fecal concentrations of putrescine and spermidine, while cadaverine and spermine were reduced. Spano et al. [56] observed that lactic acid bacteria (LAB) strains may produce biogenic amines by enzymatic decarboxylation of amino acids when exposed to acidic stress conditions. Therefore, since the fermentation of FOS resulted in lower $\mathrm{pH}$ values, the higher concentrations of cadaverine and putrescine that were observed in the present study may be the result of acid tolerance mechanisms activated by LAB. On the other hand, low protein digestibility resulted in higher concentrations of putrescine, presumably because of increased proteolysis. Interestingly, concentrations of spermine at $6 \mathrm{~h}$ and spermidine at $24 \mathrm{~h}$ of fermentation were lowered by high dietary protein level. At present, we do not have an explanation for this finding. However, based on the present results, biogenic amines, unlike ammonia and BCFA, do not seem to represent an accurate indicator for bacterial proteolytic metabolism.

After $24 \mathrm{~h}$ of incubation, high dietary protein level resulted in lower counts of lactobacilli and enterococci whereas low protein digestibility tended to increase counts of $C$. perfringens. Similar results were observed in other studies with dogs $[9,37]$ where the administration of diets rich in animal derived protein resulted in increased growth of proteolytic bacteria at the expense of LAB, and these effects were even more evident when dogs were fed diets based on low quality protein sources. Conversely, Nery et al. [10] did not observe any variation in $C$. perfringens fecal counts in dogs receiving diets formulated with different protein content and protein sources. According to the definition given by Roberfroid [57], prebiotics are non-digestible substances that are added to an animal's diet to provide a source of energy for beneficial bacterial strains residing in the hindgut. As such, prebiotics would be expected to increase intestinal counts of beneficial bacteria, such as LAB and bifidobacteria. In the present study, FOS failed to increase fecal counts of $\mathrm{LAB}$ and bifidobacteria and even resulted, after 24 h of incubation, in lower counts of Lactobacillus spp. Several studies with sometimes conflicting results have been conducted in order to investigate the effects of FOS administration on the composition of canine intestinal microbiota. In a study by Swanson et al. [26], feeding adult dogs with $2 \mathrm{~g}$ of FOS per day resulted in higher counts of bifidobacteria and lactobacilli. Conversely, Flickinger et al. [27] found that the use of FOS reduced C. perfringens in dog feces, without exerting any influence on the fecal population of lactobacilli and bifidobacteria. Similarly, other authors $[8,44,58]$ reported no effects of FOS administration on fecal counts of $L A B$ and bifidobacteria in dogs. It has been reported by several authors [59-61] that bifidobacteria are inconsistently detected in canine feces. However, other authors $[26,29]$ found greater fecal concentrations of bifidobacteria in dogs. In the present study, bifidobacteria were not affected by experimental diets and their concentration in fermentation liquid was $6.8 \log$ cells $/ \mathrm{mL}$. However, in this study, feces from dogs used as donors were not individually analyzed so that is not possible to know if bifidobacteria were present in all animals. Finally, it is worthy to mention that bacterial populations were analyzed by DNA analysis techniques in only a few of the cited studies $[8,29,37,60,61]$, while in the others bacteria were enumerated on selective media $[9,10,26,27,44,58,59]$.

\section{Conclusions}

Results from the present study showed that diets rich in protein may exert negative influences on the canine intestinal ecosystem, slightly increasing the presence of ammonia and reducing counts of lactobacilli and enterococci. Moreover, the presence of poorly digestible protein resulted in lower concentrations of VFA. Conversely, administration of FOS may improve metabolism of canine intestinal microbiota, reducing ammonia concentrations and enhancing VFA production.

\begin{abstract}
Abbreviations
ADF: acid detergent fiber; BCFA: branched-chain fatty acids; CP: crude protein; DM: dry matter; dp: degree of polymerization; FOS: fructooligosaccharides; HP HD: high protein high digestibility diet; HP LD: high protein low digestibility diet; LAB: lactic acid bacteria; LP HD: low protein high digestibility diet; LP LD: low protein low digestibility diet; NDF: neutral detergent fiber; VFA: volatile fatty acids; WCAB: Wilkins Chalgren Anaerobe Broth.
\end{abstract}

\section{Competing interests}

The authors declare that they have no competing interests.

\section{Authors' contributions}

CP and CGV carried out the in vitro study and the following chemical and microbiological analyses. CS carried out the determination of biogenic amines. GB designed and supervised the study, carried out data analysis and reviewed the manuscript. GZ participated in the study design. CP, CGV, EN and MG wrote the manuscript. All authors have read and approved the final manuscript. 


\section{Acknowledgements}

Authors are thankful to Effeffe Pet Food Sp.A. (Italy) for providing the commercial diets used in the study.

\section{Author details}

'Department of Veterinary Medical Sciences, University of Bologna, via Tolara di Sopra 50, 40064 Ozzano Emilia, Italy. ${ }^{2}$ Department for Life Quality Studies, University of Bologna, Corso d'Augusto 237, 47921 Rimini, Italy.

\section{Received: 4 May 2015 Accepted: 3 March 2016}

\section{Published online: 12 March 2016}

\section{References}

1. Round $J$, Mazmanian SK. The gut microbiota shapes intestinal immune responses during health and disease. Nat Rev Immunol. 2009:9:313-23.

2. Tomomatsu H. Health effects of oligosaccharides. Food Technol. 1994;48: $61-5$.

3. Suchodolski JS. Intestinal microbiota of dogs and cats: a bigger world than we thought. Vet Clin North Am Small Anim Pract. 2011;41:261-72.

4. Marques TM, Wall R, Ross RP, Fitzgerald GF, Ryan CA, Stanton C. Programming infant gut microbiota: influence of dietary and environmental factors. Curr Opin Biotechnol. 2010;21:149-56.

5. Patra AK. Responses of feeding prebiotics on nutrient digestibility, faecal microbiota composition and short-chain fatty acid concentrations in dogs: a meta-analysis. Animal. 2011;5:1743-50.

6. Flickinger EA, Fahey GC. Pet food and feed applications of inulin, oligofructose and other oligosaccharides. Br J Nutr. 2007;87 Suppl 2:297-300.

7. Howard MD, Kerley MS, Sunvold GD, Reinhart GA. Source of dietary fiber fed to dogs affects nitrogen and energy metabolism and intestinal microflora populations. Nutr Res. 2000;20:1473-84.

8. Barry KA, Hernot DC, Middelbos IS, Francis C, Dunsford B, Swanson KS, Fahey GC. Low-level fructan supplementation of dogs enhances nutrient digestion and modifies stool metabolite concentrations, but does not alter fecal microbiota populations. J Anim Sci. 2009;87:3244-52.

9. Zentek J, Marquart B, Pietrzak T, Ballevre O, Rochat F. Dietary effects on bifidobacteria and clostridium perfringens in the canine intestinal tract. J Anim Physiol Anim Nutr (Berl). 2003;87:397-407.

10. Nery J, Goudez R, Biourge V, Tournier C, Leray V, Martin L, Thorin C, Nguyen $\mathrm{P}$, Dumon $\mathrm{H}$. Influence of dietary protein content and source on colonic fermentative activity in dogs differing in body size and digestive tolerance. J Anim Sci. 2012;90:2570-80.

11. Vervaeke IJ, Dierick NA, Demeyer DI, Decuypere JA. Approach to the energetic importance of fibre digestion in pigs. II. An experimental approach to hindgut digestion. Anim Feed Sci Technol. 1989;23:169-94.

12. Biagi G, Cipollini I, Grandi M, Zaghini G. Influence of some potential prebiotics and fibre-rich foodstuffs on composition and activity of canine intestinal microbiota. Anim Feed Sci Technol. 2010;159:50-8.

13. Sunvold GD, Fahey Jr GC, Merchen NR, Reinhart GA. In vitro fermentation of selected fibrous substrates by dog and cat fecal inoculum: influence of diet composition on substrate organic matter disappearance and short-chain fatty acid production. J Anim Sci. 1995;73:1110-22.

14. Association of Official Analytical Chemists (A.O.A.C.). Official methods of analysis. 17th ed. Gaithersburg: AOAC Int; 2000.

15. Van Soest PJ, Robertson JB, Lewis BA. Methods for dietary fiber, neutral detergent fiber and nonstarch polysaccharides in relation to animal nutrition. J Dairy Sci. 1991;74:3583-97.

16. Biagi G, Piva A, Moschini M, Vezzali E, Roth FX. Effect of gluconic acid on piglet growth performance, intestinal microflora, and intestinal wall morphology. J Anim Sci. 2006;84:370-8.

17. Stefanelli C, Carati D, Rossoni C. Separation of N1- and N8-acetylspermidine isomers by reversed-phase column liquid chromatography after derivatization with dansyl chloride. J Chromatogr. 1986;375:49-55.

18. Smiricky-Tjardes MR, Flickinger EA, Grieshop CM, Bauer LL, Murphy MR, Fahey Jr GC. In vitro fermentation characteristics of selected oligosaccharides by swine fecal microflora. J Anim Sci. 2003;81:2505-14.

19. Williams BA, Bosch MW, Boer H, Verstegen MWA, Tamminga S. An in vitro batch culture method to assess potential fermentability of feed ingredients for monogastric diets. Anim Feed Sci Technol. 2005;123-124:445-62.

20. Bosch G, Pellikaan WF, Rutten PGP, van der Poel AFB, Verstegen MWA Hendriks WH. Comparative in vitro fermentation activity in the canine distal gastrointestinal tract and fermentation kinetics of fiber sources. J Anim Sci. 2008:86:2979-89.

21. Depauw S, Bosch G, Hesta M, Whitehouse-Tedd K, Hendriks WH, Kaandorp J, Janssens GPJ. Fermentation of animal components in strict carnivores: a comparative study with cheetah fecal inoculum. J Anim Sci. 2012:90:2540-8.

22. Payne AN, Zihler A, Chassard C, Lacroix C. Advances and perspectives in in vitro human gut fermentation modeling. Trends Biotechnol. 2012;30:17-25.

23. Gibson GR, McCartney AL, Rastall RA. Prebiotics and resistance to gastrointestinal infections. Br J Nutr. 2007;93 Suppl 1:31-4.

24. McQuaid TS. Medical management of a patent ductus venosus in a dog. Can Vet J. 2005;46:352-6.

25. Pinna C, Stefanelli C, Biagi G. In vitro effect of dietary protein level and nondigestible oligosaccharides on feline fecal microbiota. J Anim Sci. 2014; 92:5593-602.

26. Swanson KS, Grieshop CM, Flickinger EA, Bauer LL, Chow J, Wolf BW, Garleb KA, Fahey Jr GC. Fructooligosaccharides and Lactobacillus acidophilus modify gut microbial populations, total tract nutrient digestibilities and fecal protein catabolite concentrations in healthy adult dogs. J Nutr. 2002;132: 3721-31.

27. Flickinger EA, Schreijen EMWC, Patil AR, Hussein HS, Grieshop CM, Merchen $N R$, et al. Nutrient digestibilities, microbial populations, and protein catabolites as affected by fructan supplementation of dog diets. J Anim Sci. 2003;81:2008-18.

28. Hesta M, Janssens GPJ, Millet S, De Wilde R. Prebiotics affect nutrient digestibility but not faecal ammonia in dogs fed increased dietary protein levels. Br J Nutr. 2003;90:1007-14.

29. Middelbos IS, Fastinger ND, Fahey GC. Evaluation of fermentable oligosaccharides in diets fed to dogs in comparison to fiber standards. Anim Sci. 2007:85:3033-44

30. Stevens CE, Hume ID. Contributions of microbes in vertebrate gastrointestinal tract to production and conservation of nutrients. Physiol Rev. 1998;78:393-427.

31. Topping DL, Clifton PM. Short-chain fatty acids and human colonic function: Roles of resistant starch and non-starch polysaccharides. Physiol Rev. 2001; 81:1031-64.

32. Chapman MA, Grahn MF, Hutton M, Williams NS. Butyrate metabolism in the terminal ileal mucosa of patients with ulcerative colitis. Br J Surg. 1995; 82:36-8.

33. Roediger WE. Role of anaerobic bacteria in the metabolic welfare of the colonic mucosa in man. Gut. 1980;21:793-8.

34. Twomey LN, Pluske JR, Rowe JB, Choct M, Brown W, Pethick DW. The effects of added fructooligosaccharide (Raftilose ${ }^{\oplus 95}$ ) and inulinase on faecal quality and digestibility in dogs. Anim Feed Sci Technol. 2003;108:83-93.

35. Propst EL, Flickinger EA, Bauer LL, Merchen NR, Fahey Jr GC. A doseresponse experiment evaluating the effects of oligofructose and inulin on nutrient digestibility, stool quality, and fecal protein catabolites in healthy adult dogs. J Anim Sci. 2003;81:3057-66.

36. Hang I, Heilmann RM, Grützner N, Suchodolski JS, Steiner JM, Atroshi F, Sankari S, Kettunen A, de Vos WM, Zentek J, Spillmann T. Impact of diets with a high content of greaves-meal protein or carbohydrates on faecal characteristics, volatile fatty acids and faecal calprotectin concentrations in healthy dogs. BMC Vet Res. 2013:9:201.

37. Zentek J, Fricke S, Hewicker-Trautwein M, Ehinger B, Amtsberg G, Baums C. Dietary protein source and manufacturing processes affect macronutrient digestibility, fecal consistency, and presence of fecal Clostridium perfringens in adult dogs. J Nutr. 2004;134(Suppl):2158-61.

38. Nousiainen J. Comparative observations on selected probiotics and olaquindox as feed additives for piglets around weaning. J Anim Physiol Anim Nutr (Berl). 1991;66:224-30.

39. Lin HC, Visek WJ. Large intestinal pH and ammonia in rats: dietary fat and protein interactions. J Nutr. 1991;121:832-43.

40. Vogt B, Frey FJ. Lactulose and renal failure. Scand J Gastroenterol Suppl. 1997;222:100-1.

41. Butterworth RF. Role of circulating neurotoxins in the pathogenesis of hepatic encephalopathy: potential for improvement following their removal by liver assist devices. Liver Int. 2003;23:5-9.

42. Kolida S, Tuohy K, Gibson GR. Prebiotic effects of inulin and oligofructose. $\mathrm{Br}$ J Nutr. 2007;87 Suppl 2:193-7.

43. De Godoy MRC, Kerr KR, Fahey GC. Alternative dietary fiber sources in companion animal nutrition. Nutrients. 2013;5:3099-117. 
44. Strickling JA, Harmon DL, Dawson KA, Gross KL. Evaluation of oligosaccharide addition to dog diets: influences on nutrient digestion and microbial populations. Anim Feed Sci Technol. 2000;86:205-19.

45. Beynen AC, Baas JC, Hoekemeijer PE, Kappert HJ, Bakker MH, Koopman JP, Lemmens AG. Faecal bacterial profile, nitrogen excretion and mineral absorption in healthy dogs fed supplemental oligofructose. J Anim Physio Anim Nutr (Berl). 2002;86:298-305.

46. Rasmussen HS, Holtug K, Mortensen PB. Degradation of amino acids to short-chain fatty acids in humans: An in vitro study. Scand J Gastroenterol. 1988;23:178-82.

47. Nordgaard I, Mortensen PB, Langkilde AM. Small intestinal malabsorption and colonic fermentation of resistant starch and resistant peptides to shortchain fatty acids. Nutrition. 1995;11:129-37.

48. Smith EA, Macfarlane GT. Dissimilatory amino acid metabolism in human colonic bacteria. Anaerobe. 1997:3:327-37.

49. Macfarlane GT, Gibson GR, Beatty E, Cummings JH. Estimation of short-chain fatty acid production from protein by human intestinal bacteria based on branched-chain fatty acid measurements. FEMS Microbiol Ecol. 1992;10:81-8.

50. Kuzmuk KN, Swanson KS, Tappenden KA, Schook LB, Fahey Jr GC. Diet and age affect intestinal morphology and large bowel fermentative end-product concentrations in senior and young adult dogs. J Nutr. 2005;135:1940-5.

51. Scott KP, Gratz SW, Sheridan PO, Flint HJ, Duncan SH. The influence of diet on the gut microbiota. Pharmacol Res. 2013;69:52-60.

52. Rodriguez M, Carneiro C, Feijó M, Júnior C, Mano S. Bioactive amines: Aspects of quality and safety in food. Food Nutr Sci. 2014;5:138-46.

53. Moret S, Smela D, Populin T, Conte LS. A survey on biogenic amine content of fresh and preserved vegetables. Food Chem. 2005;89:355-61.

54. Barry KA, Wojcicki BJ, Middelbos IS, Vester BM, Swanson KS, Fahey Jr GC. Dietary cellulose, fructooligosaccharides, and pectin modify fecal protein catabolites and microbial populations in adult cats. J Anim Sci. 2010;88: 2978-87.

55. Beloshapka AN, Duclos LM, Vester Boler BM, Swanson KS. Effects of inulin or yeast cell-wall extract on nutrient digestibility, fecal fermentative endproduct concentrations, and blood metabolite concentrations in adult dogs fed raw meat-based diets. Am J Vet Res. 2012;73:1016-23.

56. Spano G, Russo P, Lonvaud-Funel A, Lucas P, Alexandre H, Grandvalet C, Coton E, Coton M, Barnavon L, Bach B, Rattray F, Bunte A, Magni C, Ladero V, Alvarez M, Fernández M, Lopez P, de Palencia PF, Corbi A, Trip H, Lolkema S. Biogenic amines in fermented foods. Eur J Clin Nutr. 2010;64 Suppl 3:95-100.

57. Roberfroid MB. Prebiotics: The concept revisited. J Nutr. 2007;137 Suppl 2: 830-7.

58. Swanson KS, Grieshop CM, Flickinger EA, Merchen NR, Fahey GC. Effects of supplemental fructooligosaccharides and mannanoligosaccharides on colonic microbial populations, immune function and fecal odor components in the canine. J Nutr. 2002;132 Suppl 2:1717-9.

59. Willard MD, Simpson RB, Cohen ND, Clancy JS. Effects of dietary fructooligosaccharide on selected bacterial populations in feces of dogs. Am J Vet Res. 2000;61:820-5.

60. Vanhoutte T, Huys G, De Brandt E, Fahey Jr GC, Swings J. Molecular monitoring and characterization of the faecal microbiota of healthy dogs during fructan supplementation. FEMS Microbiol Lett. 2005;249:65-71.

61. Beloshapka AN, Dowd SE, Suchodolski JS, Steiner JM, Duclos L, Swanson KS. Fecal microbial communities of healthy adult dogs fed raw meat-based diets with or without inulin or yeast cell wall extracts as assessed by 454 pyrosequencing. FEMS Microbiol Ecol. 2013;84:532-41.

\section{Submit your next manuscript to BioMed Central and we will help you at every step:}

- We accept pre-submission inquiries

- Our selector tool helps you to find the most relevant journal

- We provide round the clock customer support

- Convenient online submission

- Thorough peer review

- Inclusion in PubMed and all major indexing services

- Maximum visibility for your research

Submit your manuscript at www.biomedcentral.com/submit 